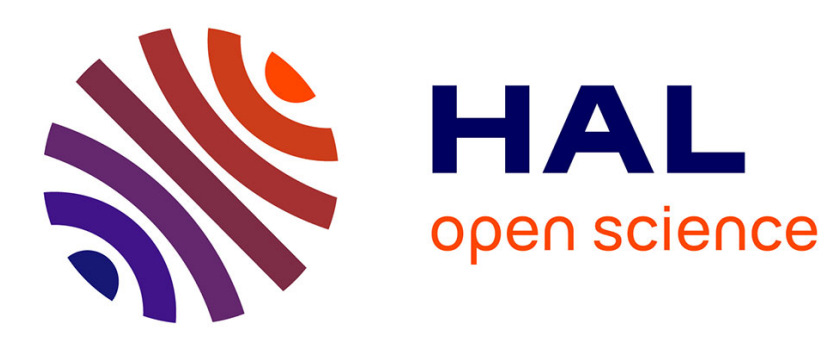

\title{
Absorbent Porous Paper Reveals How Earthquakes Could be Mitigated
}

\author{
G. Tzortzopoulos, P. Braun, Ioannis Stefanou
}

\section{To cite this version:}

G. Tzortzopoulos, P. Braun, Ioannis Stefanou. Absorbent Porous Paper Reveals How Earthquakes Could be Mitigated. Geophysical Research Letters, 2021, 48 (3), 10.1029/2020GL090792 . hal03168395

\section{HAL Id: hal-03168395 \\ https://hal.science/hal-03168395}

Submitted on 13 Mar 2021

HAL is a multi-disciplinary open access archive for the deposit and dissemination of scientific research documents, whether they are published or not. The documents may come from teaching and research institutions in France or abroad, or from public or private research centers.
L'archive ouverte pluridisciplinaire HAL, est destinée au dépôt et à la diffusion de documents scientifiques de niveau recherche, publiés ou non, émanant des établissements d'enseignement et de recherche français ou étrangers, des laboratoires publics ou privés. 
Not subject to U.S. copyright. Accepted for publication in Geophysical Research Letters. Published in 2020 American Geophysical Union. Further reproduction or electronic distribution is not permitted.

\title{
Absorbent porous paper reveals how earthquakes could be mitigated
}

\author{
G. Tzortzopoulos ${ }^{1}$, P. Braun ${ }^{1}$, I. Stefanou ${ }^{1}$ \\ ${ }^{1}$ Institut de Recherche en Génie Civil et Mécanique, Ecole Centrale de Nantes \\ 1 Rue de la Noë, Nantes 44321, France
}

Key Points:

- From an energetic point of view, absorbent porous paper can be an ideal, low-cost surrogate rock material for studying induced seismicity.

- Segmentation of faults and sequential fluid injection in each segment can mitigate potential earthquakes by at least one order of magnitude.

- We show that fault segmentation, segment-activation rate and stress state predominantly control the result of applied injection strategies.

Corresponding author: Ioannis Stefanou, ioannis.stefanou@ec-nantes.fr 


\begin{abstract}
Earthquakes nucleate when large amounts of elastic energy, stored in the earth's crust, are suddenly released due to abrupt sliding over a fault. Fluid injections can reactivate existing seismogenic faults and induce/trigger earthquakes by increasing fluid pressure. Here we develop an analogous experimental system of simultaneously loaded and wetted absorbent porous paper to quantify theoretically the process of wetting-induced earthquakes. This strategy allows us to gradually release the stored energy by provoking low intensity tremors. We identify the key parameters that control the outcome of the applied injection strategy, which include the initial stress state, fault segmentation, and segment-activation rate. Subsequent injections, initiated at high stress levels, can drive the system faster towards its instability point, nucleating a large earthquake. Starting at low stress levels, however, they can reduce the magnitude of the natural event by at least one unit.
\end{abstract}

\title{
Plain Language Summary
}

Understanding natural and anthropogenic seismicity is a major scientific challenge. Here we present a novel analogue fault model using absorbent porous paper, which gives new insights on earthquake mitigation. When scaled to in-situ conditions, the porous paper model represents a natural seismic rupture of magnitude $M_{\mathrm{w}}=5.9$. By progressively wetting it, we simulate fluid injections in the earth's crust and draw analogies to largescale industrial projects. In our experiments, each injection is accompanied by tremors, which progressively release energy and modify the energy budget of the system. Without precise knowledge of the fault properties, we risk driving the system faster towards an unexpected large seismic event. However, provided that the model's key parameters fault segmentation, segment-activation rate, and stress state - are well known or controlled, the natural rupture can be mitigated by at least one unit. We expect that these results will facilitate risk reduction in current fluid injection projects and inspire earthquake mitigation strategies for real tectonic faults.

\section{Introduction}

It is well recognized today that humans can cause earthquakes (Raleigh et al., 1976; McGarr et al., 2002; Guglielmi et al., 2015; Foulger et al., 2018). Examples of anthropogenic seismicity involve earthquakes provoked by large artificial water reservoirs such as dams (Gupta, 2002), mining (Li et al., 2007), underground nuclear explosions (Hamilton et al., 1972) or by fluid injections in the earth's crust (Ellsworth, 2013; Rubinstein \& Mahani, 2015; Garagash \& Germanovich, 2012; Schultz et al., 2020). The latter type of anthropogenic seismicity is of particular interest, due to the numerous ongoing industrial applications (Rubinstein \& Mahani, 2015; Hosseini et al., 2018). These anthropogenic seismic events could shift the Gutenberg and Richter (1954) power law, which describes the relationship between the total number of earthquakes and their magnitudes, towards smaller events.

This idea is similar to the one traditionally used for reducing the risk of large snow avalanches. Snow avalanches follow the same frequency-magnitude distributions as natural earthquakes do (Birkeland \& Landry, 2002). Nowadays, it is common practice to avoid large avalanches by provoking smaller ones. Similarly, large earthquakes could be probably mitigated by inducing low intensity tremors. This is what is called here earthquake mitigation. This notion was first mentioned by Raleigh et al. (1976), but has not been explored further since.

Surrogate materials can effectively substitute in-situ rock and gouge materials (Rosenau et al., 2017). Some examples of such materials are sandpaper (King, 1975), cardboard (Heslot et al., 1994), pasta (Knuth \& Marone, 2007), steel (Popov et al., 2012), hydrogel (Latour et al., 2013) and puffed rice (Einav \& Guillard, 2018). Here we use absorbent porous paper as an analogue fault material to explore earthquake mitigation. We show 
that it can be an ideal low-cost surrogate material for reproducing earthquake-like instabilities in the laboratory. Wetting the absorbent paper allows us not only to weaken the material but also to induce small instabilities. By deriving adequate scaling laws (see supporting information §6), we can simulate fluid injections and study the transition from seismic (unstable, sudden) to aseismic (stable, creep-like) slip of an ideal fault (Stefanou, 2019; Cappa et al., 2019).

\section{Paper-quakes vs. earth-quakes}

Consider an isolated planar dip-slip fault, as depicted in Figure 1a, with a length of $L_{\mathrm{ac}}^{\text {real }}=6.5 \mathrm{~km}$ dipped at an angle of $60^{\circ}$ (see also supporting information $\S 5$ ). Based on its properties and assuming a square rupture area $\left(A^{\text {real }} \approx\left(L_{\mathrm{ac}}^{\text {real }}\right)^{2}\right)$, this fault leads to an earthquake of $M_{\mathrm{w}} \approx 6$ (see supporting information $\S 6$ ). The energy budget is contained in a single sheet of absorbent paper which, consequently, can represent this fault (see also supporting information §1-2) if strained as shown in Figure 1b. Long range interactions with other faults are not considered herein.

The energetic equivalence of the paper analogue with a real fault can be observed in Figures 1c-e. The progressive accumulation of elastic energy in the rocks surrounding the fault zone is taken into account by a spring attached at the one end of the sheet (Figures 1d-e). The apparent stiffness of the spring is chosen to represent the real system. A constant slow velocity is applied at the extremity of this spring, simulating the slow far-field tectonic loading. Finally, paper has a non-negligible softening branch that simulates the critical slip distance $d_{\mathrm{c}}$ of faults (Scholz, 2002) (Figure 1f).

We can also simulate fluid injections by simply wetting the paper sheet. In a fault system, the apparent friction drops when fluids under pressure are injected into the fault zone due to the decrease of the effective normal stress. Similarly, porous paper shows a noticeable stress drop when it is wetted due to the reduction of its strength (Figures If and 2c). The ratio of the shear stress drop of real faults to the strength weakening of porous paper is defined here by the scaling factor $a$, which is a free parameter in our model (see also supporting information $§ 6$ ). Finally, opposite to wetting, healing could be considered by drying the paper stripes, which could potentially lead to repeatedly growing slip events. However, this is out of the scope of the present work, which focuses on earthquake mitigation by fault reactivation.

Notice that the fluid diffusion process which takes places during injections in wellbores can be considered in our analogue model in two ways, by water absorption of porous paper and by progressive wetting of many isolated stripes (see Figures $1 \mathrm{~b}$ and e and Section 4). Assuring that tectonic loading is much slower (see Section 5 for more details) than diffusion, only the latter way is examined here.

The configuration shown in Figures $1 \mathrm{~b}$ and e leads to a sudden release of the elastic energy upon rupture, in the same way as the energy stored in the rocks surrounding the fault zone is released during an earthquake. Note that typical failure modes II and/or III that take place during seismic slip in faults are represented here by a mode I failure of the porous paper. These systems are equivalent in terms of energy budget (Nussbaum \& Ruina, 1987), provided that appropriate scaling laws are applied. By using these scaling laws (see supporting information $\S 6$ ) and measuring the elastic energy $E_{\mathrm{R}}^{\text {paper }}$ that accompanies paper failure in the surrogate system, one can estimate the earthquake magnitude $M_{\mathrm{w}}$ of the real system as follows:

$$
M_{\mathrm{w}}=\frac{2}{3} \log _{10}\left(E_{\mathrm{R}}^{\text {paper }}\right)+6.36 \quad\left(E_{\mathrm{R}}^{\text {paper }} \text { in } \mathrm{Nm}\right)
$$

In Figure 2a, we present the force-displacement evolution of a paper sheet that is put under tension as described above. In the beginning, the porous paper shows a linear 


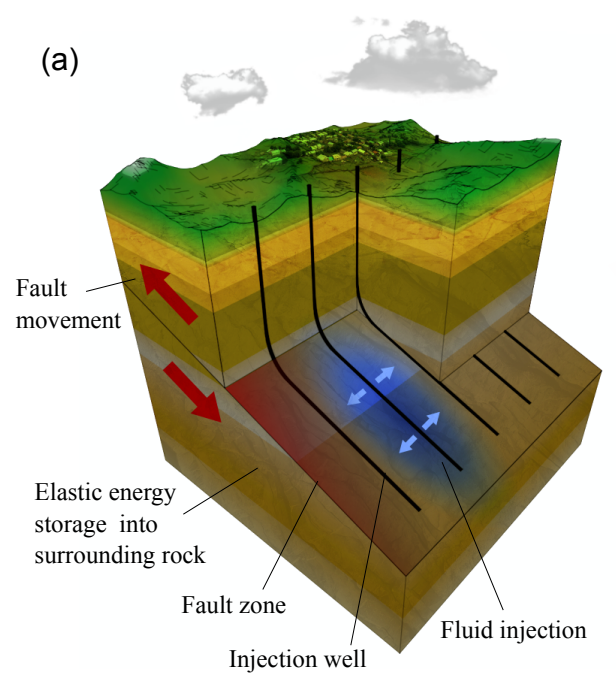

(d)
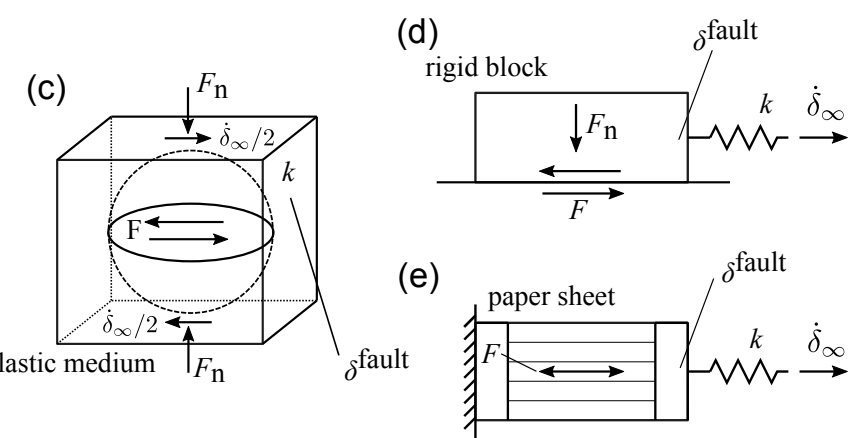

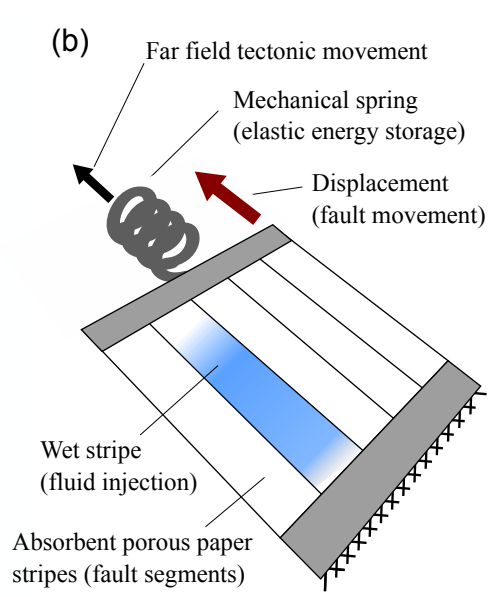

(f)

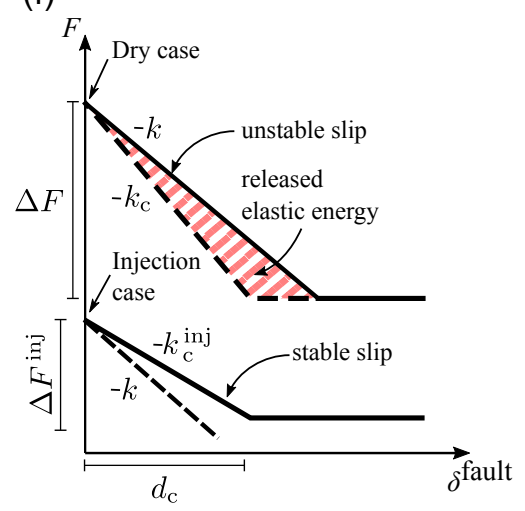

Figure 1. (a) Simplified dip-slip fault where the fault zone area is divided in five segments parallel to the slip direction. Five wells allow to inject fluid into each segment independently. (b) Surrogate laboratory experiment consisting of five parallel stripes of absorbent paper, held together at their ends by clamps. Far-field movement is applied through a mechanical spring. The paper stripes can be wetted individually. (c) Pre-existing fault within an elastic medium of stiffness $k$, loaded by a very low velocity, $\dot{\delta}_{\infty}$. Normal forces $F_{\mathrm{n}}$ act on the fault, while frictional forces $F$ are generated along the interface (Reid, 1910). (d) Spring-slider model (Scholz, 2002), composed of a rigid block, which is pulled through a spring over a rough surface. (e) Paperspring model, where a stripe of paper is pulled through an elastic spring. (f) Schematic forcedisplacement diagram in which the post-peak properties are modified due to fluid injection on the fault (wetting in the porous paper case), allowing transition from unstable to stable slip.

behavior up to its peak strength. Then, a fracture appears in the paper sheet and the spring is unloaded abruptly. The energy that is released during the unloading is equal to $E_{\mathrm{R}}^{\text {paper }}=E_{\mathrm{R}}^{0}=0.201 \mathrm{Nm}$ (hatched area), corresponding to an equivalent earthquake of $M_{\mathrm{w}}=5.9$ according to Eq. (1). This dynamic instability can also be observed by the velocity pulse shown in Figure 2b, illustrating the analogy between paper-quakes and earth-quakes (Kanamori \& Brodsky, 2004) (see also supporting information Movie S1). 

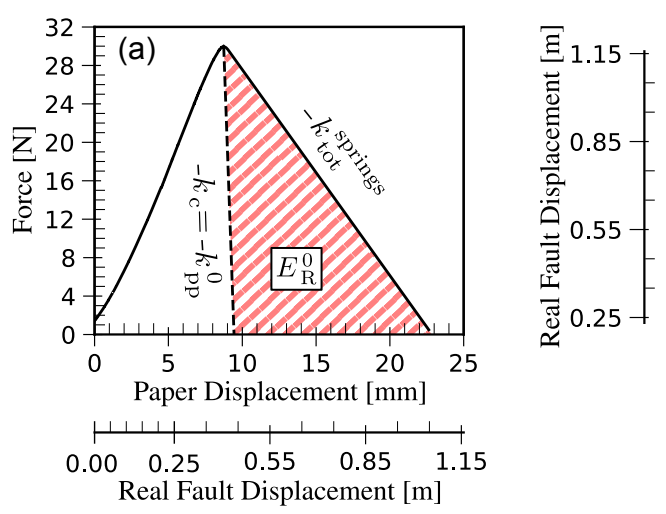

(b)
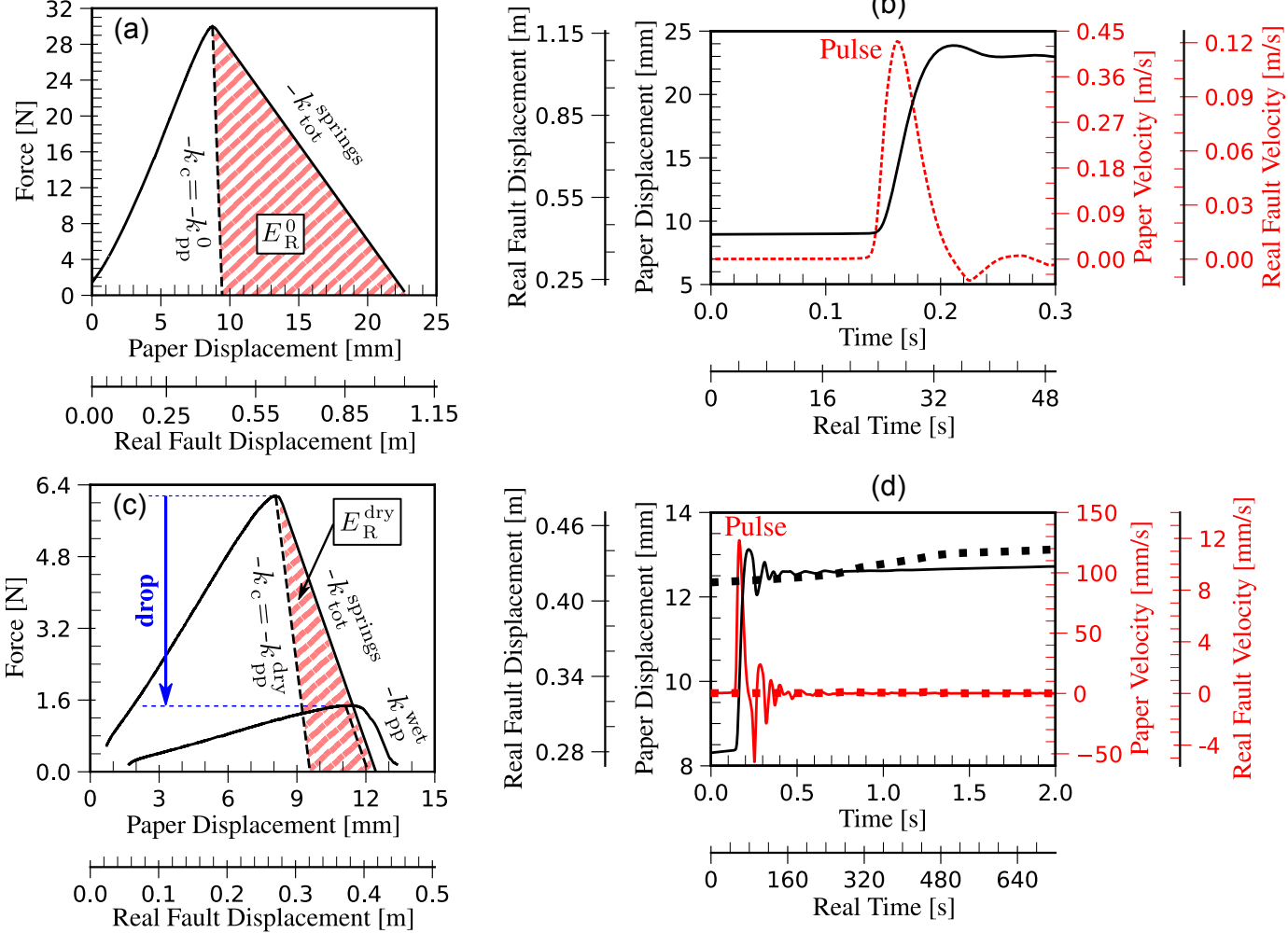

(d)

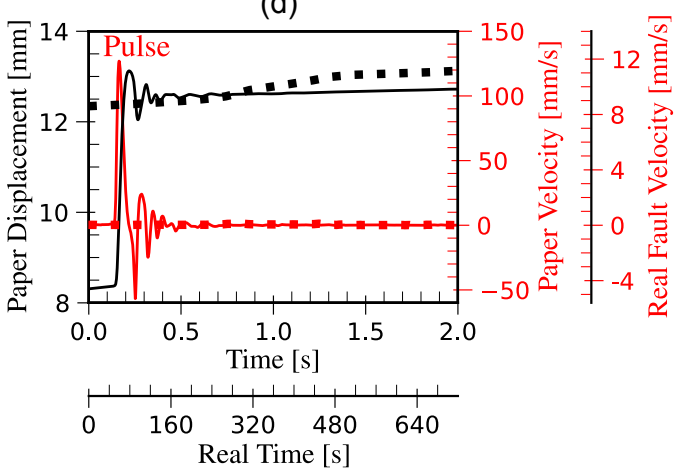

Figure 2. (a) Force-paper displacement diagram of a paper sheet experiment, showing paper behavior without a spring (dashed line) and with a spring attached to one end (solid line). (b) Pulse-like velocity (dotted line) of the dynamic paper sheet experiment, with corresponding slip (solid line). (c) Force-paper displacement diagram of representative dry and wet experiments, for a single paper stripe. Post-peak slope reduction $\left(k_{\mathrm{pp}}^{\mathrm{dry}}>k_{\mathrm{pp}}^{\text {wet }}\right)$ and force drop are observed. In this example, a dynamic instability happens in the dry case $\left(k_{\text {tot }}^{\text {springs }}<k_{\mathrm{pp}}^{\text {dry }}\right)$ releasing energy $E_{R}^{d r y}$. In the wet case no instability occurs $\left(k_{\text {tot }}^{\text {springs }}>k_{\mathrm{pp}}^{\text {wet }}\right)$. (d) Paper displacement (black) and velocity (red) evolution with time for dry (solid lines) and wet (dotted lines). The stabilizing effect of wetting is apparent. The additional axes scale the respective quantities to the real fault case (cf. supporting information $\S 6$ ).

\section{From seismic to aseismic rupture}

A seismic rupture, i.e. an earthquake, is a dynamic instability that happens when the (elastic) unloading of the rocks surrounding the fault zone cannot be counterbalanced by fault friction. A necessary but not sufficient condition for the occurrence of this instability is the reactivation of the fault. We say that a fault is reactivated when the shear stress on the fault area is high enough for frictional slip to take place. However, this slip can be slow (aseismic) or sudden and abrupt (seismic), depending on the amount of slip weakening (Figure 1f). It can be shown that the condition for sudden, unstable slip is (Dieterich, 1979; Scholz, 2002; Kanamori \& Brodsky, 2004; Stefanou, 2019):

$$
k<k_{\mathrm{c}}=\frac{\Delta F}{d_{\mathrm{c}}}
$$

where $k$ is the apparent stiffness of the rocks surrounding the fault zone for the real system, and $k_{c}$ is the critical stiffness. In a real scenario, the drop of shear force is $\Delta F=A^{\text {real }} \Delta \tau^{\text {real }}$, 
where $\Delta \tau^{\text {real }}$ is the apparent shear stress drop of the fault zone. The stiffness $k$ is proportional to the effective elastic shear modulus of the surrounding rocks $G^{\text {real }}$, and inversely proportional to the fault length $L_{\mathrm{ac}}^{\text {real }}$, i.e. $k \propto G^{\text {real }} / L_{\mathrm{ac}}^{\text {real }}$. Moreover, according to Coulomb friction $\tau=\mu \sigma_{\mathrm{n}}^{\prime}$, where $\sigma_{\mathrm{n}}^{\prime}=\sigma_{\mathrm{n}}-p_{\mathrm{w}}$ is the effective normal stress, $\sigma_{\mathrm{n}}$ is the total normal stress, which is a fraction of the overburden load, depending on the tectonic setting, and $p_{\mathrm{w}}$ is the fluid pressure.

Therefore, fluid injections have a double effect. On the one hand, they can reactivate a fault by increasing $p_{\mathrm{w}}$, reduce friction and promote frictional slip (Cappa et al., 2019). On the other hand, they can reduce $k_{\mathrm{c}}$ as they make the post-peak slope less steep (Scuderi et al., 2017; Lockner et al., 1991) (Figure 1f). Consequently, in an earthquake mitigation attempt, one could adjust fluid pressure in such a way to avoid sudden, seismic slip and assure stable, creep-like rupture (Stefanou, 2019).

\section{Earthquake mitigation by fault segmentation and fluid injections}

Controlling the fluid pressure simultaneously, across an entire fault of several kilometers, seems impossible with current technologies. Yet, we could imagine to divide the potential rupture area into several zones and inject fluids through a network of well-bores (Figure 1a). In this way, the energy stored in the system could be in theory released gradually, mitigating the maximum earthquake magnitude.

The rupture area of our fault scenario is divided into five segments and so is the paper sheet, as shown in Figures 1a-b. In order to have a better understanding of the behavior of the segmented paper sheet (Figure 1b) under wetting, we tested first a single segment (Figure S4a). In Figure 2c, we show the transition from seismic rupture to an aseismic one by wetting. While the dry sample fails suddenly, liberating energy $E_{\mathrm{R}}^{\text {dry }}=$ $9.2 \mathrm{Nmm}$ (hatched area), the wet sample fails progressively with $E_{\mathrm{R}}^{\text {wet }} \approx 0$, i.e. aseismically (see also supporting information Movie S2).

Figure $2 \mathrm{~d}$ corroborates the aseismic failure of the single stripe when wet. In particular, the time-profiles of displacement and velocity are presented and compared for both dry and wet samples. While the dry sample slips abruptly, the wet sample reaches the same displacement in an almost constant, slow velocity, which is two orders of magnitude smaller than the peak velocity of the dry case (see also supporting information Movie S2). If we apply our scaling laws on the experimental data (see supporting information $\S 6$ ), the dry single-stripe test gives an earthquake of magnitude $M_{\mathrm{w}}=4.5$, which is nucleated in a normal fault with a length of $L_{\mathrm{ac}}^{\text {real }}=1.3 \mathrm{~km}$.

Focusing on our surrogate experiment, five stripes (see supporting information Figure S4b) are put in tension and are wetted subsequently to simulate multiple discrete fluid injections. A certain amount of fluid is injected each time assuring fast saturation all over the respective fault segment. Until the completion of the injection strategy, no more fluid is injected on an already saturated segment. The injection program starts before reaching instability, at a stress level $R=20 \%$ (Figure 3a), where $R$ is the ratio of the tensile force at the first injection over the maximum tensile resistance. Wetting one stripe is performed approximately every $1 \mathrm{~mm}$ of total displacement (segment-activation rate $=3$ stripes $/ \mathrm{min}$ ). This displacement corresponds to $\sim 5 \mathrm{~cm}$ of average slip over the real fault zone (see also supporting information $\S 4$ and Movies S1 and S3).

Each fluid injection is accompanied by an instantaneous stress drop and stress redistribution over the intact, dry porous paper stripes (Harris, 1998; Cappa et al., 2019) (Figure 3a). In this setup, the redistribution is quasi-uniform and may not capture phenomena related to real fault geometries. Due to these stress drops, energy is released abruptly, corresponding to the triggering of small dynamic events (hatched areas). Ideally, we would like to minimize their magnitudes or assure aseismic slip after each injection. The maximum magnitude 

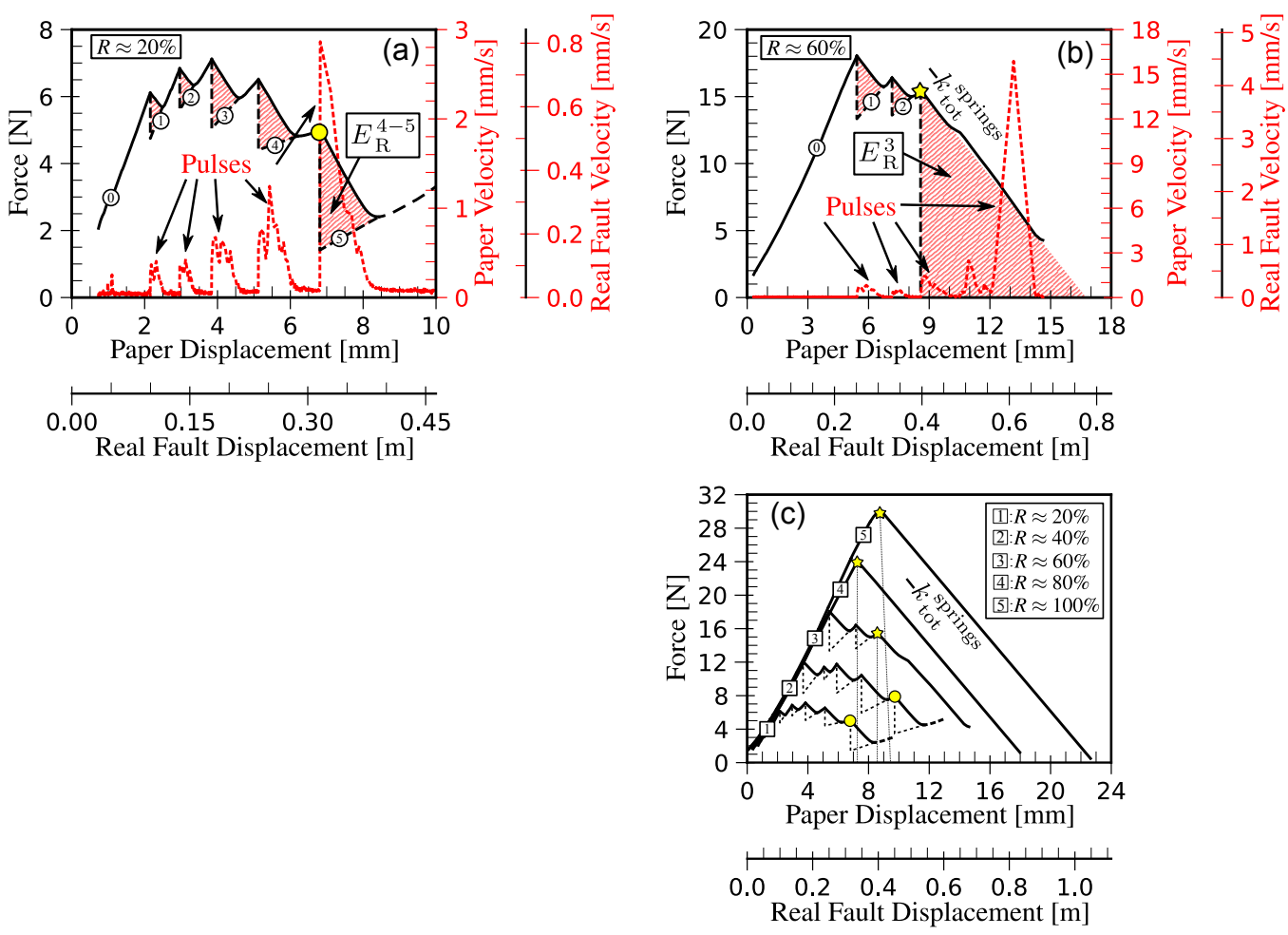

Figure 3. Wetting scenarios starting at $R=20 \%$, (a), and $R=60 \%$, (b). Force (equivalent friction, solid lines) and velocity (equivalent slip-rate, dotted lines) evolve with displacement (equivalent slip). Circled numbers depict the number of wetted paper stripes (reactivated fault segments). In (a), the maximum earthquake event takes place at the fifth injection (filled circle) and releases $E_{\mathrm{R}}^{4-5}$. In (b), the sample fails dynamically at the third injection (star) and all remaining elastic energy is released abruptly (rupture of the entire fault area outside the injection area). (c) Force-paper displacement for scenarios started at different stress levels $R$. The star indicates that global failure occurs before wetting all the stripes (i.e. rupture outside the injection region).

among these smaller events characterizes the effectiveness of the earthquake mitigation strategy.

Figure 3a shows the energy release and the developed velocities during this injection program in our experiment. In the same plot we present also the corresponding magnitudes of displacement and velocity that would develop in the real fault system. A sequence of dynamic events are triggered with magnitudes: $M_{\mathrm{w}}^{0-1}=3.9, M_{\mathrm{w}}^{1-2}=3.9, M_{\mathrm{w}}^{2-3}=$ $4.3, M_{\mathrm{w}}^{3-4}=4.4$ and $M_{\mathrm{w}}^{4-5}=4.7$. It is worth emphasizing that the released energy increases with subsequent slip and it is maximum after the last injection $\left(E_{\mathrm{R}}^{4-5}=2.94 \mathrm{Nmm}\right)$, which is 68 times smaller than the energy of the large natural event. Therefore, we were able to mitigate the initial natural earthquake event of magnitude $M_{\mathrm{w}}=5.9$ to five smaller earthquake events, whose maximum magnitude (filled circle in Figure $3 \mathrm{a}$ ) is $M_{\mathrm{w}}=$ 4.7. In terms of velocities (dotted line in Figure 3a), after each injection, we observe a distinct pulse corresponding to the released dynamic energy.

The system behaved differently when the injections started at a stress level ratio $R=60 \%$ (Figure 3b, see also supporting information Movie S4). In this case, three dynamic events are triggered with magnitudes: $M_{\mathrm{w}}^{0-1}=4.7, M_{\mathrm{w}}^{1-2}=4.5$ and $M_{\mathrm{w}}^{3}=5.5$. A 
large event followed the third injection (filled star in Figure 3b), leading to seismic rupture. Energetically, this event $\left(M_{\mathrm{w}}^{3}=5.5\right)$ is equivalent to the natural earthquake event $\left(M_{\mathrm{w}}=\right.$ 5.9, see also Figures 2a-b).

In Figure 3c, we show the energy release for injections started at different stress level ratios with the same segment-activation rate as before. In the case of $R \approx 100 \%$, no injection can be carried out, as any tiny perturbation leads directly to an earthquake nucleation (filled star) of magnitude $M_{\mathrm{w}}^{0}=5.9$ (Figures 2a-b). At $R=40 \%$, all five injections are accomplished as in $R=20 \%$. These injections result in a series of five induced earthquakes where their maximum magnitude (filled circle) is $M_{\mathrm{w}}^{4-5}=4.8$. When $R=80 \%$, though, a dynamic rupture occurs (filled star) after the first injection leading to an earthquake event of $M_{\mathrm{w}}^{1}=5.8$, similar to the case of $R=60 \%$ (Figure $3 \mathrm{~b}$ ).

The experimental observations show clearly that as the stress level at the initiation of the injection process becomes smaller, so does the magnitude of the subsequent events. In other words, a sequence of earthquakes could be triggered, showing a maximum magnitude which is at least one order of magnitude smaller than the natural earthquake.

Notice that our study is in agreement with the findings of the modeling work of van der Elst et al. (2016). As we can observe in Figure 3c, the natural earthquake event (curve 5) is the maximum event that can be nucleated in a fault in terms of energy, no matter how much fluid volume has been injected into the fault and no matter when the injection commences.

\section{Discussion}

The proposed analogy between uniaxial tension experiments of absorbent porous paper and a real fault system is based on energy considerations. Our model is a pertinent example for building understanding regarding possible mitigation of the earthquake phenomenon (for a synthesis of the main assumptions and limitations we refer to the supporting information $\S 7$ ). Intuitively, our approach could help to limit anthropogenic seismicity (Shapiro et al., 2013) during fluid injections in the earth's crust, in parallel with the Traffic Light System (TLS) method (Bommer et al., 2006; Edwards et al., 2015) used in deep geothermal projects.

It is worth emphasizing that, according to our experiments, preceding small seismic events do not guarantee the avoidance of large ones. Even though the released energy in induced events is always smaller than the natural event, subsequent injections can drive the system faster towards its instability point, provoking a large event (Figures 3b-c). These events ( $R=60 \%$ and $80 \%$ in our experiments) would correspond to anthropogenic seismicity when significant amounts of fluid are injected in the earth's crust, close to critically stressed tectonic faults. On the other hand, we showed scenarios of progressive wetting, where the maximum seismic moment could be reduced by one order of magnitude (Figures 3a and c). An important aspect, necessary for the possible mitigation in this scenario, is the relatively low initial stress level $(R=20 \%$ and $40 \%$ in our experiments). Therefore, the earthquake mitigation strategy can succeed only if the injection process starts at relatively low stress levels.

Besides the in-situ stress level, the paper experiments uncovered two additional factors which govern the magnitude of induced events. These factors are the segment-activation rate, which expresses the number of segments that are wetted per unit of time, and the number of segments that our samples are divided into. In order to explore the response of the fault system under the variation of these two additional factors, we use a multi spring-slider model (see supporting information $§ 3-4$ ).

The segment-activation rate can be seen as the rate under which we force the system to release its internal (potential/elastic) energy. According to our experiments and this 


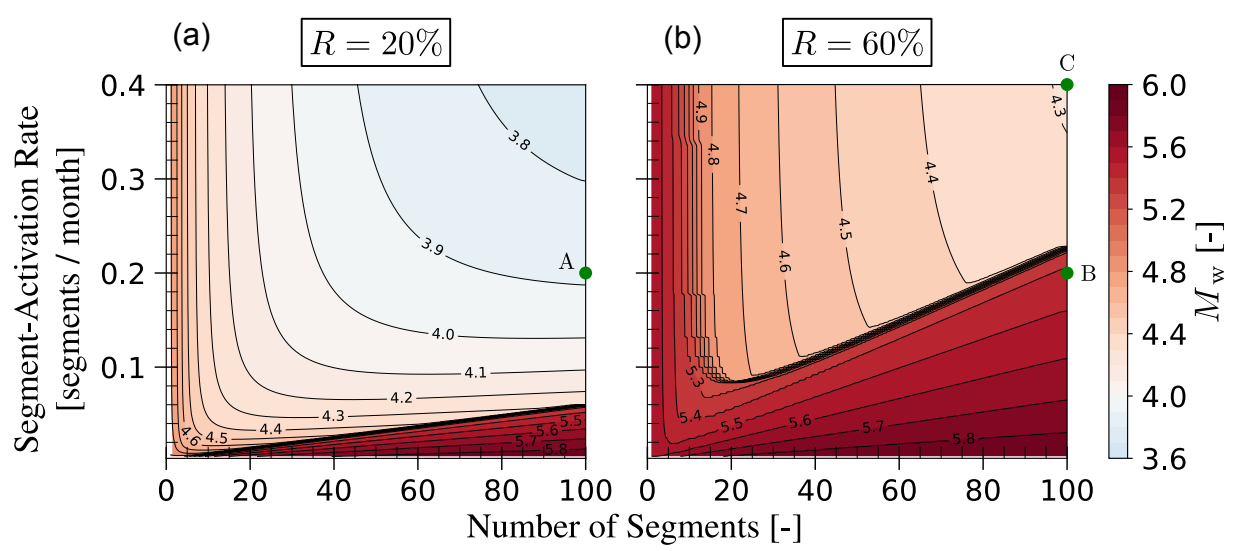

Figure 4. The maximum magnitude is plotted in function of the segment-activation rate, number of fault segments and two different stress levels, based on our fault scenario: (a) $R=20 \%$ and (b) $R=60 \%$.

model, this rate has to be fast enough to outpace the progressive energy build-up due to the far-field tectonic displacements. When our segment-activation rate is fast enough, the system releases its internal energy and the large event is avoided. It seems that this is the case in many industrial projects that involve injections of large amounts of fluids in the earth's crust (McGarr, 2014; Guglielmi et al., 2015; Grigoli et al., 2018).

According to Hosseini et al. (2018), fluid boundary conditions play an important role in induced seismicity. In our experimental work, fluid boundary conditions are expressed through segmentation by adjusting plastic (impermeable) barriers between the stripes (see also supporting information $\S 4$ ). Each injection leads to only one seismic event resulting in a linear relation between the number of cumulative events in the fault and the time, presuming constant segment-activation rate. Eventually, the number of segments, that a fault has been divided into, depicts the maximum number of stimulated events.

In the absence of impermeable barriers, high number of segments would represent better the physical reality, where the distribution of injection pressure does not occur instantly over a region (paper segment), but follows a diffusion process (Bhattacharya \& Viesca, 2019). The diffusion process due to fluid injection in faults is equivalent to the progressive wetting of paper stripes. If we assume, for instance, a high-permeable damage fault zone with hydraulic diffusivity of the surrounding rocks of the order of $10^{-1}$ to $10^{1} \mathrm{~m}^{2} / \mathrm{s}$ (values taken from Lim et al., 2020), the time it takes for each segment $\left(1.3 \times 6.5 \mathrm{~km}^{2}\right)$ to be saturated after fluid injection ranges between 10 to 980 days, respectively. In Figure $3 \mathrm{a}$, where the experimental results of the proposed injection strategy are presented, the segment-activation rate is 3 stripes/min which corresponds to 0.01 segments/month in a real case scenario. Therefore, the above evaluated diffusion time is sufficient enough in order to assure fast saturation of each segment.

Figure 4 presents the computed magnitude of the maximum earthquake event that would occur, as a function of segment-activation rate and number of segments. For instance, under a given rate of one injection per five months and for $R=20 \%$, one obtains a maximum $M_{\mathrm{w}} \approx 3.9$, when segmenting the fault into 100 parts (point A, Figure 4a). For $R=$ $60 \%$, though, the injection program leads to a large event of $M_{\mathrm{w}} \approx 5.4$, close to the natural one of $M_{\mathrm{w}} \approx 5.9$ (point $\mathrm{B}$, Figure $4 \mathrm{~b}$ ). Doubling the rate from one to two injections per five months reduces the maximum event to $M_{\mathrm{w}} \approx 4.3$ (point C, Figure $4 \mathrm{~b}$ ). 
Despite the numerous uncertainties in the properties of the earth's crust (Cornet, 2019), our experiments (Figure 3c) and model (Figure 4) reveal the strong dependency between the outcome of the injection strategy and the three aforementioned key parameters (initial stress level, segment-activation rate and segmentation). By adequately controlling these parameters, we managed to artificially reduce the stored elastic energy in an analogue tectonic fault. However, in practice these parameters are hard to control and other strategies based on the mathematical theory of control could provide rigorous alternatives (Stefanou, 2019, 2020).

\section{Data Availability Statement}

The raw data from all the performed experiments of this study are publicly available in Zenodo repository in Tzortzopoulos et al. (2020).

\section{Acknowledgments}

Funding: This work was supported by the European Research Council (ERC) under the European Union Horizon 2020 research and innovation program (Grant agreement no. 757848 CoQuake), http://coquake.com.

Contribution: All authors contributed to the analysis and writing the manuscript. Competing interests: The authors declare that they have no competing interests.

The authors thank Prof. I. Einav for his fruitful comments and our scientific discussions. The authors also would like to thank Dr. Pierrick Guégan for his help in the preparation and calibration of the traction apparatus in the laboratory.

\section{References}

Bhattacharya, P., \& Viesca, R. C. (2019). Fluid-induced aseismic fault slip outpaces pore-fluid migration. Science, 364(6439), 464-468. Retrieved from https://science.sciencemag.org/content/364/6439/464 doi: 10.1126/science.aaw7354

Birkeland, K. W., \& Landry, C. C. (2002). Power-laws and snow avalanches. Geophysical Research Letters, 29(11), 49-1-49-3. Retrieved from https:// agupubs.onlinelibrary.wiley.com/doi/abs/10.1029/2001GL014623 doi: 10.1029/2001GL014623

Bommer, J. J., Oates, S., Cepeda, J. M., Lindholm, C., Bird, J., Torres, R., ... Rivas, J. (2006). Control of hazard due to seismicity induced by a hot fractured rock geothermal project. Engineering Geology, 83(4), 287 - 306. Retrieved from http://www.sciencedirect.com/science/article/pii/ S0013795205003108 doi: https://doi.org/10.1016/j.enggeo.2005.11.002

Cappa, F., Scuderi, M. M., Collettini, C., Guglielmi, Y., \& Avouac, J.-P. Stabilization of fault slip by fluid injection in the laboratory and in situ. Science Advances, 5(3). Retrieved from https://advances.sciencemag.org/ content/5/3/eaau4065 doi: 10.1126/sciadv.aau4065

Cornet, F. H. (2019). The engineering of safe hydraulic stimulations for egs development in hot crystalline rock masses. Geomechanics for Energy and the Environment, 100151. Retrieved from http://www.sciencedirect.com/ science/article/pii/S2352380819300280 doi: https://doi.org/10.1016/ j.gete.2019.100151

Dieterich, J. H. (1979). Modeling of rock friction: 1. experimental results and constitutive equations. Journal of Geophysical Research: Solid Earth, 84(B5), 2161-2168. Retrieved from https://agupubs.onlinelibrary.wiley.com/ doi/abs/10.1029/JB084iB05p02161 doi: 10.1029/JB084iB05p02161

Edwards, B., Kraft, T., Cauzzi, C., Kästli, P., \& Wiemer, S. (2015). Seismic monitoring and analysis of deep geothermal projects in St Gallen and Basel, 
Switzerland. Geophysical Journal International, 201(2), 1022-1039. Retrieved from https://doi.org/10.1093/gji/ggv059 doi: 10.1093/gji/ggv059

Einav, I., \& Guillard, F. (2018). Tracking time with ricequakes in partially soaked brittle porous media. Science Advances, 4(10). Retrieved from https://advances.sciencemag.org/content/4/10/eaat6961 doi: 10.1126/sciadv.aat6961

Ellsworth, W. L. (2013). Injection-induced earthquakes. Science, 341(6142). Retrieved from https://science.sciencemag.org/content/341/6142/ 1225942 doi: $10.1126 /$ science. 1225942

Foulger, G. R., Wilson, M. P., Gluyas, J. G., Julian, B. R., \& Davies, R. J. (2018). Global review of human-induced earthquakes. Earth-Science Reviews, 178, 438 - 514. Retrieved from http://www.sciencedirect.com/ science/article/pii/S001282521730003X doi: https://doi.org/10.1016/ j.earscirev.2017.07.008

Garagash, D. I., \& Germanovich, L. N. (2012). Nucleation and arrest of dynamic slip on a pressurized fault. Journal of Geophysical Research: Solid Earth, 117(B10). Retrieved from https://agupubs.onlinelibrary.wiley.com/doi/ abs/10.1029/2012JB009209 doi: 10.1029/2012JB009209

Grigoli, F., Cesca, S., Rinaldi, A. P., Manconi, A., López-Comino, J. A., Clinton, J. F., ... Wiemer, S. (2018). The november $2017 \mathrm{mw} 5.5$ pohang earthquake: A possible case of induced seismicity in south korea. Science, 360 (6392), 10031006. Retrieved from https://science.sciencemag.org/content/360/6392/ 1003 doi: $10.1126 /$ science.aat2010

Guglielmi, Y., Cappa, F., Avouac, J.-P., Henry, P., \& Elsworth, D. Seismicity triggered by fluid injection-induced aseismic slip. Science, 348(6240), 1224-1226. Retrieved from https://science.sciencemag.org/ content/348/6240/1224 doi: 10.1126/science.aab0476

Gupta, H. K. (2002). A review of recent studies of triggered earthquakes by artificial water reservoirs with special emphasis on earthquakes in koyna, india. Earth-Science Reviews, 58(3), 279 - 310. Retrieved from http:// www.sciencedirect.com/science/article/pii/S0012825202000636 doi: https://doi.org/10.1016/S0012-8252(02)00063-6

Gutenberg, B., \& Richter, C. F. (1954). Seismicity of the earth and associated phenomena (2nd ed.). Princeton University Press, Princeton, N. J.

Hamilton, R. M., Smith, B. E., Fischer, F. G., \& Papanek, P. J. Earthquakes caused by underground nuclear explosions on pahute mesa, nevada test site. Bulletin of the Seismological Society of America, 62(5), 1319-1341.

Harris, R. A. (1998). Introduction to special section: Stress triggers, stress shadows, and implications for seismic hazard. Journal of Geophysical Research: Solid Earth, 103(B10), 24347-24358. Retrieved from https:// agupubs .onlinelibrary.wiley.com/doi/abs/10.1029/98JB01576 doi: 10.1029/98JB01576

Heslot, F., Baumberger, T., Perrin, B., Caroli, B., \& Caroli, C. (1994). Creep, stickslip, and dry-friction dynamics: Experiments and a heuristic model. Phys. Rev. E, 49, 4973-4988. Retrieved from https://link.aps.org/doi/10.1103/ PhysRevE.49.4973 doi: 10.1103/PhysRevE.49.4973

Hosseini, S. M., Goebel, T. H. W., Jha, B., \& Aminzadeh, F. (2018). A probabilistic approach to injection-induced seismicity assessment in the presence and absence of flow boundaries. Geophysical Research Letters, 45(16), 81828189. Retrieved from https://agupubs.onlinelibrary.wiley.com/doi/abs/ 10.1029/2018GL077552 doi: 10.1029/2018GL077552

Kanamori, H., \& Brodsky, E. E. (2004). The physics of earthquakes. Reports on Progress in Physics, 67(8), 1429-1496. Retrieved from https://doi.org/10 .1088\%2F0034-4885\%2F67\%2F8\%2Fr03 doi: 10.1088/0034-4885/67/8/r03 
King, C.-Y. (1975). Model seismicity and faulting parameters. Bulletin of the Seismological Society of America, 65(1), 245-259.

Knuth, M., \& Marone, C. (2007). Friction of sheared granular layers: Role of particle dimensionality, surface roughness, and material properties.

Geochemistry, Geophysics, Geosystems, 8(3). Retrieved from https:// agupubs.onlinelibrary.wiley.com/doi/abs/10.1029/2006GC001327 doi: 10.1029/2006GC001327

Latour, S., Voisin, C., Renard, F., Larose, E., Catheline, S., \& Campillo, M. (2013). Effect of fault heterogeneity on rupture dynamics: An experimental approach using ultrafast ultrasonic imaging. Journal of Geophysical Research: Solid Earth, 118(11), 5888-5902. Retrieved from https://agupubs.onlinelibrary .wiley.com/doi/abs/10.1002/2013JB010231 doi: 10.1002/2013JB010231

Li, T., Cai, M., \& Cai, M. (2007). A review of mining-induced seismicity in china. International Journal of Rock Mechanics and Mining Sciences, 44(8), 1149 1171. Retrieved from http://www.sciencedirect.com/science/article/ pii/S1365160907000810 doi: https://doi.org/10.1016/j.ijrmms.2007.06.002

Lim, H., Deng, K., Kim, Y., Ree, J.-H., Song, T.-R. A., \& Kim, K.-H. (2020). The $2017 \mathrm{mw} 5.5$ pohang earthquake, south korea, and poroelastic stress changes associated with fluid injection. Journal of Geophysical Research: Solid Earth, 125(6), e2019JB019134. Retrieved from https:// agupubs.onlinelibrary.wiley.com/doi/abs/10.1029/2019JB019134 (e2019JB019134 2019JB019134) doi: 10.1029/2019JB019134

Lockner, D. A., Byerlee, J. D., Kuksenko, V., Ponomarev, A., \& Sidorin, A. (1991). Quasi-static fault growth and shear fracture energy in granite. Nature, 350(6313), 39-42. Retrieved from https://doi.org/10.1038/350039a0 doi: $10.1038 / 350039 \mathrm{a} 0$

McGarr, A. (2014). Maximum magnitude earthquakes induced by fluid injection. Journal of Geophysical Research: Solid Earth, 119(2), 1008-1019. Retrieved from https://agupubs.onlinelibrary.wiley.com/doi/abs/10.1002/ 2013JB010597 doi: 10.1002/2013JB010597

McGarr, A., Simpson, D., \& Seeber, L. $\quad$ (2002). 40 - case histories of induced and triggered seismicity. In W. H. Lee, H. Kanamori, P. C. Jennings, \& C. Kisslinger (Eds.), International handbook of earthquake and engineering seismology, part a (Vol. 81, p. 647 - 661). Academic Press. Retrieved from http://www.sciencedirect.com/science/article/pii/S0074614202802431 doi: https://doi.org/10.1016/S0074-6142(02)80243-1

Nussbaum, J., \& Ruina, A. (1987). A two degree-of-freedom earthquake model with static/dynamic friction. Pure and Applied Geophysics, 125(4), 629-656. Retrieved from http://link.springer.com/10.1007/BF00879576 doi: 10.1007/BF00879576

Pluijm, van der, R. (1999). Out-of-plane bending of masonry : behaviour and strength (Doctoral dissertation, Department of the Built Environment). (Proefschrift.) doi: 10.6100/IR528212

Popov, V., Grzemba, B., Starcevic, J., \& Popov, M. (2012). Rate and state dependent friction laws and the prediction of earthquakes: What can we learn from laboratory models? Tectonophysics, 532-535, 291-300. Retrieved from http://www.sciencedirect.com/science/article/pii/S0040195112001138 doi: https://doi.org/10.1016/j.tecto.2012.02.020

Raleigh, C. B., Healy, J. H., \& Bredehoeft, J. D. (1976). An experiment in earthquake control at rangely, colorado. Science, 191(4233), 1230-1237. Retrieved from https://science.sciencemag.org/content/191/4233/1230 doi: 10.1126/science.191.4233.1230

Reid, H. F. (1910). The Mechanics of the Earthquake, The California Earthquake of April 18, 1906. In Report of the state earthquake investigation commission, vol. 2. Washington, D. C.: Carnegie Institution of Washington. 
Rosenau, M., Corbi, F., \& Dominguez, S. (2017). Analogue earthquakes and seismic cycles: experimental modelling across timescales. Solid Earth, 8(3), 597-635. Retrieved from https://www.solid-earth.net/8/597/2017/ doi: 10.5194/se $-8-597-2017$

Rubinstein, J. L., \& Mahani, A. B. (2015). Myths and Facts on Wastewater Injection, Hydraulic Fracturing, Enhanced Oil Recovery, and Induced Seismicity. Seismological Research Letters, 86(4), 1060-1067. Retrieved from https://doi.org/10.1785/0220150067 doi: 10.1785/0220150067

Scholz, C. H. (2002). The mechanics of earthquakes and faulting (2nd ed.). Cambridge University Press. doi: 10.1017/CBO9780511818516

Schultz, R., Skoumal, R. J., Brudzinski, M. R., Eaton, D., Baptie, B., \& Ellsworth, W. (2020). Hydraulic fracturing-induced seismicity. Reviews of Geophysics, 58(3), e2019RG000695. Retrieved from https://agupubs.onlinelibrary .wiley.com/doi/abs/10.1029/2019RG000695

(e2019RG000695 2019RG000695) doi: 10.1029/2019RG000695

Scuderi, M., Collettini, C., Viti, C., Tinti, E., \& Marone, C. (2017). Evolution of shear fabric in granular fault gouge from stable sliding to stick slip and implications for fault slip mode. Geology, 45(8), 731-734. Retrieved from https://doi.org/10.1130/G39033.1 doi: 10.1130/G39033.1

Shapiro, S. A., Krüger, O. S., \& Dinske, C. (2013). Probability of inducing givenmagnitude earthquakes by perturbing finite volumes of rocks. Journal of Geophysical Research: Solid Earth, 118(7), 3557-3575. Retrieved from https://agupubs.onlinelibrary.wiley.com/doi/abs/10.1002/jgrb.50264 doi: $10.1002 /$ jgrb.50264

Stefanou, I. (2019). Controlling anthropogenic and natural seismicity: Insights from active stabilization of the spring-slider model. Journal of Geophysical Research: Solid Earth, 124(8), 8786-8802. Retrieved from https:// agupubs.onlinelibrary.wiley.com/doi/abs/10.1029/2019JB017847 doi: 10.1029/2019JB017847

Stefanou, I. (2020). Control instabilities and incite slow-slip in generalized burridgeknopoff models. arXiv:2008.03755.

Tzortzopoulos, G., Braun, P., \& Stefanou, I. (2020, dec). Paper-Quake Mitigation Strategy: Experimental Raw Data. Zenodo. Retrieved from https://doi.org/ 10.5281/zenodo. 4380988 doi: 10.5281 /zenodo.4380988

van der Elst, N. J., Page, M. T., Weiser, D. A., Goebel, T. H., \& Hosseini, S. M. (2016). Induced earthquake magnitudes are as large as (statistically) expected. Journal of Geophysical Research: Solid Earth, 121(6), 4575-4590. Retrieved from https://agupubs.onlinelibrary.wiley.com/doi/abs/10.1002/ 2016JB012818 doi: 10.1002/2016JB012818 